\title{
APPLICATIONS OF LAYERED THEORY FOR THE ANALYSIS OF FLEXIBLE PAVEMENTS
}

\author{
Nidhi.M. ${ }^{1}$, M.S.Nagakumar ${ }^{2}$ \\ ${ }^{I}$ M. Tech IV semester, Highway Technology, ${ }^{2}$ Associate Professor, Department of Civil Engineering, R. V. College of \\ Engineering, Bangalore-560059, India \\ Lion_prasad@hotmail.com,nagakumar@rvce.edu.in,msnagakumar@gmail.com
}

\begin{abstract}
Unbound granular materials used in untreated base/sub-base layers, exhibit nonlinear behavior under repeated wheel loads. The properties of the granular materials play a significant role in the performance of these pavements. Therefore, accurate modelling of the granular layers is essential in the evaluation of critical pavement responses under the application of loads, these materials exhibit stress dependent characteristics. Thus, consideration of non-linearity in these layers is necessary for accurate estimation of the pavement responses of a flexible pavement structure. The pavement responses are computed using Kenlayer computer program developed by Huang. Using the Kenlayer program, this paper examines the effect of nonlinearity in granular on critical pavement responses by conducting parametric analysis. The results indicate that the consideration of nonlinearity yields $23.13 \%$ reduction in tensile strains at the bottom of bituminous layers and $0.76 \%$ increase in compressive strains on the top of the sub grade layers and same surface deflections compared to the value obtained using linear elastic analysis. This indicates that nonlinear analysis is more realistic and accurate.
\end{abstract}

Keywords: Granular layers, Kenlayer, Nonlinearity, Pavement responses. - ***

\section{INTRODUCTION}

Most of the analytical models used for the design of flexible pavements are based on linear elastic theory which assumes that each layer is homogenous, isotropic, linearly elastic with a constant modulus of elasticity and surface layer is free of shearing and normal stresses. But in reality, the materials are nonlinear, anisotropic and inhomogeneous, and some are particulate; viscous and plastic deformations occur in addition to the elastic deformations; loadings are not usually circular or uniformly distributed and so on. In addition to this, the boundary conditions are often quite complicated and different from the conditions assumed using layered elastic theory. Hence, the methods based on theory of elasticity need to be modified to accommodate nonlinear behaviour of pavement materials This nonlinear behaviour is commonly characterized by stress dependent resilient modulus which is used as a fundamental input parameter in the application of layer theory in flexible pavements design [1,2]. The primary objective of this study is to assess the effect of nonlinearity in granular layers on various pavement responses through parametric studies by using the Kenlayer computer programme.

\subsection{Objectives of the Research Work}

1) To conduct linear and nonlinear analysis for the multiple thicknesses, CBR by using IRC as the guidelines in order to evaluate vertical compressive stress, horizontal tensile strains, vertical compressive strains, surface deflection in pavement layers using Kenlayer software.

2) To compare the linear and nonlinear elastic methods

3) To carry out the parametric studies in order to assess the effect of nonlinearity in granular layers on various pavement responses.

\section{METHODOLOGY OF THE STUDY}

\subsection{Data Collection}

The data used in this study are collected from IRC-37-2001 i.e., "Guidelines for the design of flexible pavements" and "Pavement Analysis and Design" by Yang.H.Huang, Rada and Witczak (1981), Shook et al (1982), and Thomson and Elliot (1985) The multiple thicknesses, elastic modulus of pavement component layers and CBR values are obtained from IRC guidelines, whereas nonlinear coefficients of granular and sub grade layers are collected from Pavement analysis and design.

\subsection{Method of Data Analysis}

The method used in data analysis is mechanistic-empirical method. The mechanistic empirical software called KENLAYER is used to analyze the pavement responses. The structural analysis of flexible pavement for KENLAYER is based on the Burmister layer theory. The input for analysis consists of 1. Traffic loading which includes load groups, 
contact radius, contact pressure, wheel spacing in $\mathrm{X}$ and $\mathrm{Y}$ axis, Number of points in $\mathrm{x}$ and $\mathrm{y}$ coordinates to be analyzed under multiple wheels, 2. Material properties which include modulus of elasticity, the Poisson's ratio, and the unit weight of each layer, 3.Number of layers, number of $\mathrm{z}$ coordinates and the thicknesses of each layer. These inputs are keyed in KENLAYER using menu: LAYERINP. The SI unit system is used.

\subsection{Traffic Loading}

In this study for simplification of the analysis, the dual wheels are converted into an equivalent $80 \mathrm{KN}$ single axle load (ESAL). Other items of information about the load required in LAYERINP are: 1. The contact radius of circular loaded area (CR), 2. Contact pressure on circular loaded area (CP), 3. Center to center spacing between two dual wheels along the $\mathrm{y}$ axis (YW), and 4 . Number of points in $\mathrm{x}$ and $\mathrm{y}$ coordinates to be analyzed under multiple wheels (NPT).

In this study, single axle with dual tyres need to be considered and each tire is assumed to have circular contact area. The tire spacing is assumed with a typical distance between dual tires of $35 \mathrm{~cm}$. The contact pressure in this study is $5.6 \mathrm{~kg} / \mathrm{cm}^{2}$ i.e.550kpa and contact radius is calculated as follows:

$$
\mathrm{a}=(\mathrm{P} / \mathrm{p} \pi)^{1 / 2}
$$

Where $\mathrm{a}=$ Contact radius, $\mathrm{P}=$ Total load on the tire, $\mathrm{p}=$ tire pressure, which works out to be $10.77 \mathrm{~cm}$. Wheel spacing in $\mathrm{X}$ axis is $0 \mathrm{~cm}$ (Single axle), and in $\mathrm{Y}$ axis is $35 \mathrm{cms}$. Response points are $(0,0),(0,8.75),(0,17.5)$.
In this study, the load information that keyed in LAYERINP is shown in Table 1

Table 1: Load information

\begin{tabular}{|c|c|c|c|}
\hline CR & CP & YW & NPT \\
\hline 10.77 & 550 & 35 & 3 \\
\hline
\end{tabular}

\subsection{Material Properties}

The main properties used in this study are the modulus of elasticity, the Poisson's ratio, and the unit weight of each layer. Both linear and nonlinear analysis was conducted. In linear analysis, three layers are analysed as linear elastic, whereas in nonlinear analysis, granular layer are analysed as nonlinear elastic. The thicknesses of each layer, obtained from IRC guidelines are stored in LAYINP menu. Number of zcoordinates are 2. Number of layers is 3 for linear elastic case, 7 for nonlinear base and subbase case. The elastic modulus of bituminous layer at $35 \mathrm{C}$ having $60 / 70$ grade bitumen is considered and elastic modulus of other layers are computed as per IRC guidelines. The Poisson's ratio and unit weight keyed into LAYERINP are 0.5 and $22.8 \mathrm{kN} / \mathrm{m}^{3}$ for bituminous surfacing layer, 0.35 and $21.2 \mathrm{kN} / \mathrm{m}^{3}$ for the granular layers and 0.45 and $19.6 \mathrm{kN} / \mathrm{m}^{3}$ for the subgrade layer. Table 2 shows the variation of pavement responses for various surface and granular layer thicknesses for linear elastic case

Table 2: The variation of pavement responses for various surface and granular layer thicknesses for linear elastic case

\begin{tabular}{|c|c|c|c|c|c|c|}
\hline $\begin{array}{c}\text { Thickness } \\
\text { of surfacing } \\
(\mathrm{cm})\end{array}$ & $\begin{array}{c}\text { Thickness } \\
\text { of granular } \\
\text { layer } \\
(\mathrm{cm})\end{array}$ & $\begin{array}{c}\text { Elastic } \\
\text { modulus } \\
\text { of } \\
\text { granular } \\
\text { layer } \\
(\mathrm{kPa})\end{array}$ & $\begin{array}{c}\text { Vertical } \\
\text { Compressive } \\
\text { Stress } \\
(\mathrm{kPa})\end{array}$ & $\begin{array}{c}\text { Horizontal } \\
\text { tensile } \\
\text { Micro-strains }\end{array}$ & $\begin{array}{c}\text { Vertical } \\
\text { Compressive } \\
\text { Micro-strains }\end{array}$ & $\begin{array}{c}\text { Surface } \\
\text { Deflection } \\
(\mathrm{cm})\end{array}$ \\
\hline 5 & 66.5 & 74530 & 16.44 & 1068 & 794 & 0.17 \\
\hline 6 & 69 & 75778 & 14.87 & 1027 & 721 & 0.16 \\
\hline 9.5 & 70 & 76270 & 11.84 & 524 & 580 & 0.12 \\
\hline 14 & 71 & 76758 & 9.49 & 363 & 461 & 0.099 \\
\hline
\end{tabular}


Table 3: Variation of vertical compressive stress and strains for various CBR values

\begin{tabular}{|c|c|c|}
\hline $\begin{array}{c}\text { CBR } \\
\%\end{array}$ & $\begin{array}{c}\text { Vertical } \\
\text { compressive } \\
\text { stress }(\mathrm{kPa})\end{array}$ & $\begin{array}{c}\text { Vertical compressive } \\
\text { Micro-strains }\end{array}$ \\
\hline 2 & 16.44 & 794 \\
\hline 3 & 22.71 & 721 \\
\hline 4 & 28.76 & 677 \\
\hline 5 & 34.44 & 641 \\
\hline
\end{tabular}

\subsection{Modelling Nonlinearity in Granular Layers}

The granular layer is subdivided into 5 layers with the stress point at the mid-height of each layer, with $\mathrm{PHI}=0$. The types of materials used in granular layer are gravel and crushed stone. Number of nonlinear layer and linear layers are 5 and 2 respectively. For a nonlinear layer, $\mathrm{E}$ is the elastic modulus of first iteration and a convenient $\mathrm{E}$ is assumed on the basis of Thomson and Elliot (1985) carried out as shown in the Table 4.

Table 4: Typical Elastic modulus values for different materials

\begin{tabular}{|c|c|}
\hline Material & Range in kPa \\
\hline Crushed stone & $150000-300000$ \\
\hline Gravel & $50000-300000$ \\
\hline
\end{tabular}

\subsection{Effect of Nonlinearity in Granular Layer}

Comparison of horizontal tensile strain at the bottom of bituminous layer for pavements with linear and nonlinear granular layers is shown in Fig 1. Comparison of vertical strain on the top of the sub grade is shown in Fig 2. Significant differences are noted in the critical responses in case of horizontal tensile strain. As evidenced from Fig 1, the maximum difference in case of horizontal tensile strain is $23.13 \%$, while it is only $0.76 \%$ in case of compressive strain as can be seen from Fig 2. Thus Fig 2, clearly indicates that the trend followed in case of compressive strain for nonlinear granular base and sub-base case is the same as that of linear elastic case.

\subsection{Effect of Pavement Parameters on Critical}

\section{Responses}

Surface, granular layer thicknesses and CBR values were varied to assess the effect on pavement responses. As
There are several constants required in analyzing the nonlinear elastic: $\mathrm{K}_{0}, \mathrm{~K}_{1}, \mathrm{~K}_{2}$. The coefficient of earth pressure at rest $\left(\mathrm{K}_{0}\right)$ is taken as 0.6. Allen3(1973) suggested the range of nonlinear coefficient of granular layer $\left(\mathrm{K}_{1}\right)$ is from 1800$8000 \mathrm{psi}$ and nonlinear exponent of $0.32-0.70$. The nonlinear coefficients $\mathrm{K}_{1}$ and $\mathrm{K}_{2}$ are selected from Allen's data and coefficients are varied such that the average moduli of nonlinear system are same as the moduli of linear system. Stress points must be located to determine the modulus of elasticity of each nonlinear layer. Since only the maximum stresses, strains, or deflection are required, the stress point should be located under the center of two dual wheels, with $\mathrm{XPTNOL}=0, \mathrm{YPTNOL}=\mathrm{YW} / 2=17.5 \mathrm{~cm}$, and $\mathrm{SLD}=0$. Even though the modulus of elasticity can be calculated at any point in a nonlinear granular layer, it is recommended that the $\mathrm{z}$ coordinate is located at the mid-depth of each layer.

Tables 5 and 6 shows the pavement responses for various surface and granular layer thicknesses and various CBR values for nonlinear granular case

Table 6: Variation of vertical compressive stress and strains for various $\mathrm{CBR}$ values

\begin{tabular}{|c|c|c|}
\hline $\begin{array}{c}\text { CBR } \\
\%\end{array}$ & $\begin{array}{c}\text { Vertical } \\
\text { compressive stress } \\
(\mathrm{kPa})\end{array}$ & $\begin{array}{c}\text { Vertical compressive } \\
\text { Micro-strains }\end{array}$ \\
\hline 2 & 16.44 & 794 \\
\hline 3 & 22.71 & 721 \\
\hline 4 & 28.76 & 677 \\
\hline 5 & 34.44 & 641 \\
\hline
\end{tabular}

evidenced by Tables 2 and 5, the horizontal tensile strain at the bottom of bituminous layer:

i. Decreases with an increase in surface thickness.

ii. Decreases with an increase in elastic moduli of granular layer.

In Tables 2,3,5,6, the vertical compressive strain on the top of the subgrade:

i. Decreases with an increase in granular thickness.

ii. Decreases with an increase in CBR values.

In Tables 2,3,5,6, the vertical compressive stress on the top of the subgrade:

i. Increases with an increase in CBR values.

ii. Decreases with an increase in granular thickness.

In Tables 2 and 5, the surface deflection of pavement:

i. Decreases with an increase in surface thickness. 


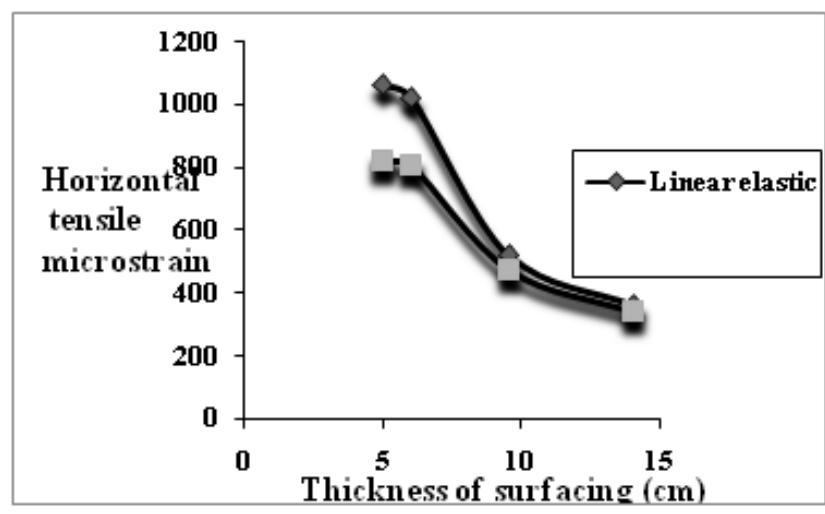

Fig 1: Comparison of linear and nonlinear horizontal tensile strains

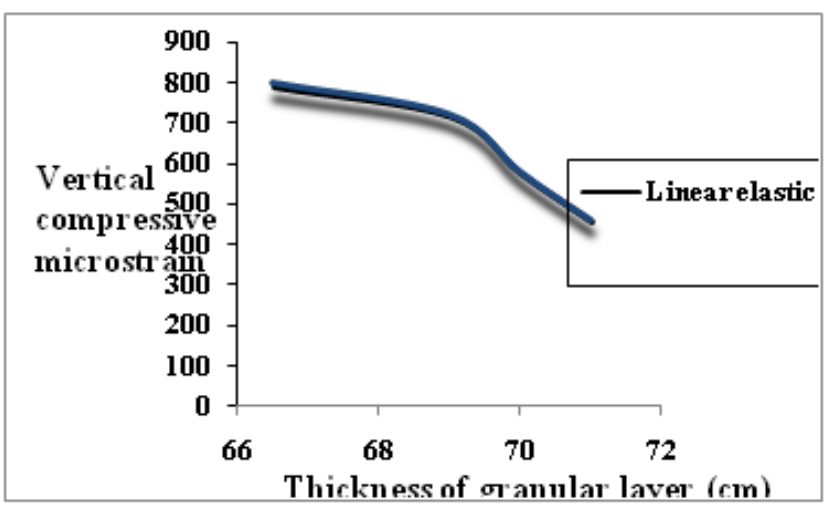

Fig 2: Comparison of linear and nonlinear vertical compressive strains

\section{CONCLUSIONS}

1. An analytical study was conducted to evaluate the effect of nonlinearity in granular layers.

2. A comparison of linear and nonlinear solutions shows that nonlinear solutions results in same surface deflection, smaller tensile strains in bituminous layers and slightly greater compressive strains in the subgrade layers.

3. These results are reasonable because deflection depends on the average moduli, tensile strain depends to a large extent on the modulus of the material immediately under the asphalt layer i.e., greater the modulus of the material immediately below the asphalt layer, smaller will be the tensile strains whereas compressive strain depends on the modulus of the material immediately above the subgrade i.e., smaller the modulus of the material immediately above the subgrade greater will be the compressive strain.

4. Thus, consideration of nonlinearity using a stress dependent resilient modulus resulted in $23.13 \%$ reduction in tensile strains at the bottom of bituminous layer and $0.76 \%$ increase in compressive strains on the top of the subgrade layers compared to the values obtained using linear elastic analysis. This indicates that the nonlinear coefficients of granular layers have more pronounced effect on tensile strain rather than on compressive strain.

5. Thus from this study, it was observed that the distresses on flexible pavement structure are considerably reduced leading to the reduction in operating and maintenance cost which will benefit the road user to a larger extent.

\section{REFERENCES}

[1] Sanaa Ahmad Masad "Sensitivity analysis of flexible pavement response and AASHTO 2002 design guide to properties of unbound layers", Research Report, May 2004, Pg. No. 1-143.

[2] Yang.H.Huang, "Pavement analysis and design", University of Kentucky, Prentice hall, Eaglewood cliffs, New Jersey, 2004.

[3] IRC 37:2001, "Guidelines for design of flexible pavements", (Second Revision)

[4] Umesh Chandra Sahoo and Kusam Sudhakar Reddy "Effect of Nonlinearity in Granular Layer on Critical Pavement Responses of Low Volume Roads", Int. J. Pavement Res. Technol., March 30 2010, Pg. No. 320325.

[5] Seong-Wan Park, and Robert L. Lytton, F, "Effect of Stress-Dependent Modulus and Poisson's Ratio on Structural Responses in Thin Asphalt Pavements", ASCE Journal, Vol. 130, No. 3, May 1, 2004, Pg.No.387-394.

[6] Rada G and Witczak M. W., (1981), "Comprehensive Evaluation of Laboratory Resilent Moduli Results for Granular Materials" Transportation research Record, 810, pp 23-33, Transportation Board,

[7] Shook, J. F., F.N. Finn, M.W. Witczak and C.L.Monismith(1982), "Thickness Design of Asphalt Pavements-The Asphalt Institute Method," Proceedings, $5^{\text {th }}$ International Conference on the Structural Design of Asphalt Pavements, Vol. 1, pp. 1744.

[8] Thompson, M.R., and R. P. Elliot(1985), "ILLIPAVE Based Response Algorithms for Design of Conventional Flexible Pavements, " Transportation Research Record 1043, pp. 50-57, Transportation Research Board. 